\title{
Hardening phenomenon of Portland cement suspensions monitored by Vicat test, isothermal calorimetry and oscillatory rheometry
}

\section{Fenômeno de endurecimento de suspensões de cimento Portland monitorado por Vicat, calorimetria isotérmica e reometria oscilatória}
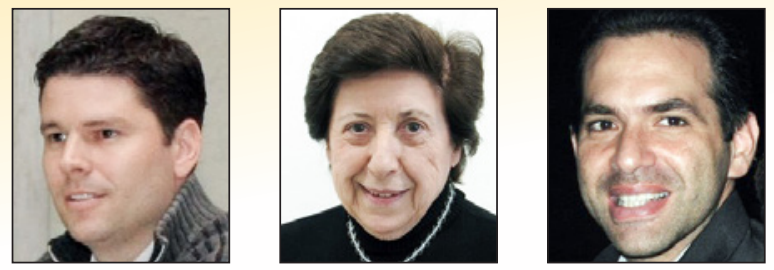

R. C. O. ROMANO

rcorjau@gmail.com

M. A. CINCOTTO a cincotto@usp.br

R. G. PILEGGI a rafael.pileggi@usp.br

\begin{abstract}
This work was conducted to evaluate the hardening phenomenon of pastes formulated with Portland cements blended with limestone filler (CPIIF), ground blast furnace slag (CPIIE) or pozzolan (CPIIZ). Vicat test, isothermal conduction calorimetry and oscillatory rheometry were the methods used to monitor this transition. The results of Vicat test indicates the faster setting time of pozzolan cement, but no information before this time was obtained. Using isothermal calorimetry was possible to monitor the related changes to the chemical reactions since the first contact with water, and using rheometry, the rate and force of cement particles agglomeration. The main purpose of this work was not extensively explain the results of these three methods, but show that they are complementary to better explain the transition from fluid-to-solid behavior in function of different kind of mineral addition.
\end{abstract}

Keywords: vicat-test, isothermal calorimetry, oscillatory rheometry, supplementary cementitious materials, Portland cement.

\section{Resumo}

Este trabalho foi realizado para avaliar o fenômeno de endurecimento de pastas formuladas com cimentos Portland compostos: calcário (CPIIF), escória granulada de alto forno (CPIIE) ou pozolana (CPIIZ). Ensaio Vicat, calorimetria de condução isotérmica e reometria oscilatória foram os métodos utilizados para monitorar tal transição. Os resultados do ensaio Vicat indicaram menor tempo de pega na composição com o cimento de pozolana, mas nenhuma informação anterior a esse tempo foi obtida. Usando calorimetria isotérmica foi possível monitorar as alterações relacionadas às reações químicas desde o primeiro contato com a água, e aplicando os conceitos de reometria, obteve-se informações sobre a taxa e força de aglomeração de partículas dos cimentos. O objetivo principal não foi explicar extensivamente os resultados destes três métodos, mas mostrar que são complementares para compreender melhor a transição do comportamento fluido para sólido em função de diferentes tipos de adição mineral. Os resultados obtidos para estes três ligantes, com diferentes SCMs, mostraram que seu desempenho é bastante diferente do ponto de vista da hidratação inicial, e consequentemente, pode ser questionado se podem ser considerados intercambiáveis em misturas de concreto ou argamassas com a mesma finalidade.

Palavras-chave: Vicat, calorimetria isotérmica, reometria oscilatória, material cimentício suplementar, cimento Portland. 


\section{Introduction}

The utilization and acceptation of blended Portland cements with granulated blast furnace slag, natural or artificial pozzolan and limestone filler as a supplementary cementitious materials (SCMs) is a common practice worldwide and is growing up [1] with the aim of to reduce the $\mathrm{CO}_{2}$ release due to the cement production.

Considering several types and quantities of SCMs, which have distinct physico-chemical and mineralogical properties, the setting transformations are distinct, although the mechanical strength at the end of 28 days are similar. This problem rises nowadays due to the great variety of new SCMs recently researched [1].

It is clear that the hardening process presents two complementary phenomena, which are very different, depending on the SCMs added [2-8]:

i. physical (agglomeration/flocculation), at the origin of the contacts between particles;

ii. chemical (rigidification), through hydrates contacting points formed between anhydrous particles under reaction.

Vicat needle test usually evaluates early-age behavior through the setting time measuring, but some limitations of this method, as following presented, do not allow deep understanding of the phenomena involved during this period [3,9-10]. From the beginning of hydration until the setting time, no result is obtained in function of the needle penetration. However, this does not mean that changes are not occurring. This is an important gap of the Vicat test, because the comprehension of physico-chemical transformations during the very early age is essential in many processes of cement compositions, mainly due to the wide options of SCMs used nowadays Stages of the concrete development like mixing, transportation, gain of consistency, stability over time, application, and others, are some aspects very important to its performance in use, that are in evolution before the setting time. Therefore, a more detailed assessment of main events associated to consolidation since the very early age is necessary, which are not perceptible by Vicat test. These phenomena may be accompanied by using oscillatory rheometry to monitor the kinetic of consolidation, and isotherma conduction calorimetry for early hydration reactions. In both cases, there is a continuously monitoring of hardening since the first contact of water-cement.

As these three methods are complementary, the results obtained can be used to better explain the hardening of Portland cements with different additions. So, follow is presented a brief explanation of each technique used in this work to facilitate the comprehension of discussions.

\subsection{Setting time using Vicat test}

The Vicat method consists in a penetration of a standard needle into a cement paste. According to the Standard Method NM 65:2003 (equivalent to ASTM C191-13), the initial time of setting occurs when the needle stops at $1 \mathrm{~mm}$ from the bottom and the final set when the needle stops at $38 \mathrm{~mm}$ ( $2 \mathrm{~mm}$ from the surface). Some researchers claim that this method has some disadvantages, and its accuracy of execution is dependent on the expertise of the technician responsible for testing [3,11].

The tests are carried out at an environmental temperature not con- sidering any climatic condition, and as reported in literature, the values obtained are empirical, useful only as a comparative basis, not corresponding to specific aspects of microstructure formation during the initial hydration or about the rheological parameters of suspensions [3,9-10]. Besides that, with the needle penetration, the formed structure is gradually broken and, therefore, the obtained result is questionable, discontinuous and does not give any information about the beginning of cement hydration.

As the setting time is measured by the depth of needle penetration in function of time, according some authors [3,12], from the rheological point of view, the only force capable to stop the penetration is the paste yield stress. Therefore, while the applied force is greater than the yield stress, the penetration goes on, but from the moment when the generated yield stress becomes lower than that force, the penetration stops, indicating the final setting time.

However, the use of Vicat test is very simple and has as advantages the low cost and easiness to use for a standard specification control, despite of being applied just only as a comparative basis. In this work, it was applied in order to correlate their results with other techniques available.

\subsection{Monitoring of hydration reactions using isothermal calorimetry}

The hydration reactions of cement and the heat release are directly related to the binder physico-chemical composition, type and content of supplementary cementitious materials for clinker substitution, chemical admixtures added, water-to-cement ratio, curing temperature, clinker phases solubility, etc. [13].

Independent of these parameters, a series of simultaneous and subsequent reactions are responsible for the gain of consistency, or loss of workability [4]. In this way, occurs the consolidation of suspensions and consequent gain on strength. However, only monitoring the chemical reaction, there is no information about the rigidity of the suspension. The information we can obtain related to the setting time is that the initial set occurs in the half way of the acceleration period, according the ASTM C1679-13.

Depending on the composition of Portland cement, different mechanisms are proposed to describe the cement hydration reactions, but are continuous and exothermic, and it can be divided into several stages, according to the flow heat, as shown in Figure 1 [14].

In the stage I, there is a quick heat release due to the neutralization of electrostatic charge in the particles surface, dissolution of calcium sulfate and alkali sulfates. There is too the dissolution of $\mathrm{C}_{3} \mathrm{~S}$ (alite) and $\mathrm{C}_{3} \mathrm{~A}$ (calcium aluminate) phases, releasing $\mathrm{K}^{+}, \mathrm{Na}^{+}$, $\mathrm{SO}_{4}^{2-}, \mathrm{Ca}^{2+}$ ions, saturating the solution. The dissolved sulfate is consumed and, in these first few minutes of reaction, small and rigid needles of ettringite (AFt) and monosulfoaluminate (AFm) plates are formed, even the formation of C-S-H plates [7,14-17]. In stage II starts the C-S-H crystallization, precipitating a layer around the cement particles, which apparently slows down the hydration reactions rate, due to formation of a barrier around the particles. During this time, called induction period, there is a gradual raise in the $\mathrm{Ca}^{2+}, \mathrm{K}^{+}, \mathrm{Na}^{+}, \mathrm{SO}_{4}^{2-}, \mathrm{OH}^{-}$and silicate $\left(\mathrm{H}_{2} \mathrm{SiO}_{4}^{2-}\right)$ ions concentration, which generally extends to about 3 hours, depending on the type of cement. 
After the $\mathrm{Ca}^{2+}$ oversaturation of the solution, starts the stage III, in which occurs the precipitation of portlandite and $\mathrm{C}-\mathrm{S}-\mathrm{H}$ needles around the anhydrous particles, forming an outer shell, with high heat release. This is the acceleration period of the reaction. With the reaction evolution, the particles links forming a three-dimensional network, gradually increasing, changing the consistency of the suspension. In this stage starts and ends the setting of cement, the sulfates are adsorbed and the Aft precipitation is prevented. After the peak of heat release, the reaction rate of $\mathrm{C}_{3} \mathrm{~S}$ decreases, following the so-called deceleration period (stage IV). The $\mathrm{C}_{3} \mathrm{~A}$ is dissolved, the adsorbed sulfates are released and the ettringite formation restarts until all sulfate is consumed. This step occurs between 10 and 20 hours; after 30 hours the excess of aluminate reacts with ettringite, forming calcium monosulfoaluminate (AFm). From that stage, the reactions are controlled by ionic diffusion and the formation of C-S-H and portlandite occur, but slowly. The anhydrous core of particles goes on hydration forming the inner shell hydrates [5,18-21].

\subsection{Monitoring consolidation using oscillatory rheometry}

The phenomena that induce consolidation in cementitious suspensions can be described as a physical contribution to hardening Therefore, the evaluation of the magnitude of attractive forces in function of time is very important $[22,23]$. As shown by Nonat et al [2], the consolidation of cementitious suspension occurs in two stages: firstly, there is the particle agglomeration due to the action of electrostatic and capillary forces, then, the formation of hydrated compounds results on the hardening.

Oscillatory tests controlling frequency and strain (called time sweep) are the most indicative for monitoring the consolidation in function of time, provided they are performed in the linear viscoelastic region - LVR, when the imposed strain is below the critical strain to break down the agglomerated structure generated. Usually, to evaluate the cementitious suspensions it is applied a strain up to $10^{-4}$, independently of water-to-cement ratio. Using this condition, there is no disruption of the hydrated structure, and the monitoring of consolidation rate is done continuously, since the start of the test.

The oscillatory tests consist in applying a sinusoidal strain $(\gamma)$ in the sample, to obtain the stress $(\tau)$, as expressed in the equations 1 and 2 .

$\gamma=\gamma_{0} \cdot \sin w t$

$\tau=\tau_{0} \cdot \sin (w t+\delta)$

$\mathrm{w}$ is the angular speed, $\mathrm{t}$ is the time, $\gamma_{0}$ is the maximum amplitude strain, $\tau_{0}$ is the yield stress and $\delta$ is the angle phase.

Ideally, when the stress and strain are in phase $(\delta=0)$ the material (a)

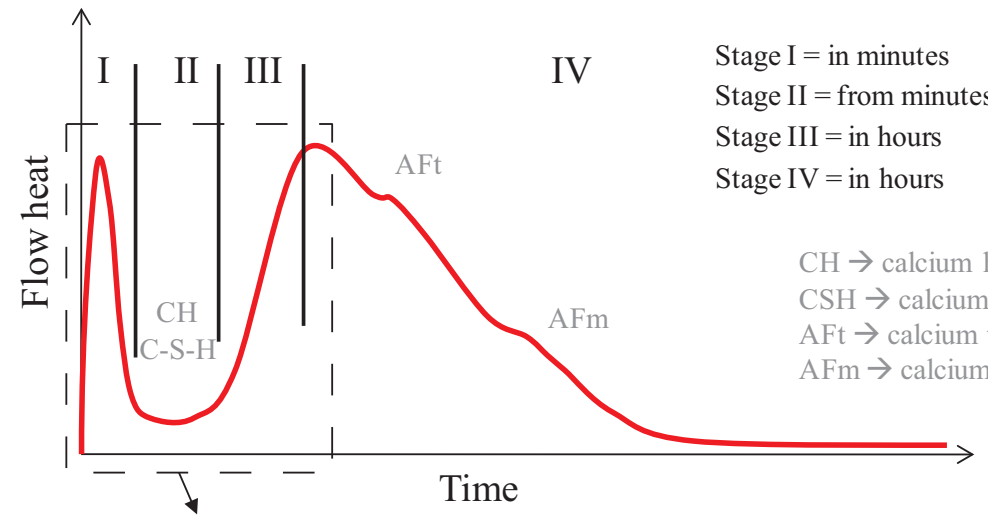

(b)

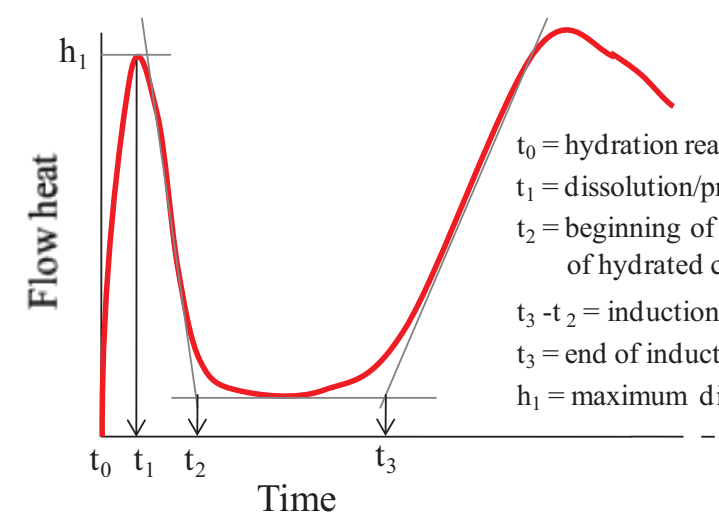

\section{Figure 1}

Illustration of the heat release in function of time. In (a), the flow heat divided in four stages is presented and in (b) what each point means 
behavior is typically Hookean, as a solid (elastic). When the stress and strain are out of phase $\left(\delta=90^{\circ}\right)$ the material shows typical Newtonian fluid behavior (viscous).

However, materials really do not behave as pure fluids or as solids during the consolidation, but present an intermediate behavior $(0$ $<\delta<90^{\circ}$ ) known as viscoelastic. Figure 2 is presented for a schematic illustration of such behavior.

From the equations 1 and 2 the complex modulus $\left(G^{*}\right)$ may be calculated in function of the ratio of maximum amplitude strain and yield stress, as shown in eq. 3 :

$$
G^{*}=\frac{\tau_{0}}{\gamma_{0}}
$$

As $\mathrm{G}^{*}$ is a complex number, it may be divided in two components: a real (called storage modulus - G') and another imaginary (G", called loss modulus), according to the equations 4 and 5 :

$$
G^{\prime}=G^{*} \cdot \cos \delta
$$

$G^{\prime \prime}=G^{*} \cdot \operatorname{sen} \delta$

As during the test the generated microstructure is not broken, the results of G' have a very close relationship with the yield stress. In this way, $\tau_{0}$ may be accompanied continuously in function of time.

Tests of dynamic-mechanical nature have as a target to establish correlations of:

i. the macroscopic properties with molecular relaxation due to conformational changes; and

ii. the micro-deformations from the molecular rearrangements.

Changes in G' occurs just because part of the applied energy is re- covered and part of the tri-dimensional network flows under stress: more resistant networks have higher storage modulus in function of time, and present close relationship with yield stress. So, using oscillatory tests as time sweep, it is possible monitoring continuously the evolution of the cement paste yield stress [4,24].

\section{Experimental procedure}

\subsection{Materials}

The work was carried out using commercial Brazilian Portland cement blended with blast furnace slag (CPIIE), limestone filler (CPIIF) and pozzolan (CPIIZ). Figure 3 shows the particle size distribution (measured by laser granulometry, Malvern, Mastersizer Longbed), real density (gas He picnometry, Multipycnometer, Quantachrome MVP 5DC) and specific surface area (BET method, Micromeritics ASAP 2010).

The real densities are very similar and the granulometric distributions are in the same range of diameters. On the other hand, the specific surface area of CPIIZ is higher than the other cements. These variations may influence the rheological properties, the consolidation rate and heat release during the hydration reaction.

Mineralogical compositions were obtained by X-ray diffraction (Empyrean, PANalytical, with detector PIXcel ${ }^{3 \mathrm{D}}$ ) and the results are presented in Figure 4.

Besides to all phases commonly observed in all cements, in the cement blended with pozzolan were observed mullite $\left(3 \mathrm{Al}_{2} \mathrm{O}_{3} \cdot 2 \mathrm{SiO}_{2}\right)$, hematite $\left(\mathrm{Fe}_{2} \mathrm{O}_{3}\right)$ and magnetite $\left(\mathrm{Fe}_{3} \mathrm{O}_{4}\right)$. In the cement blended

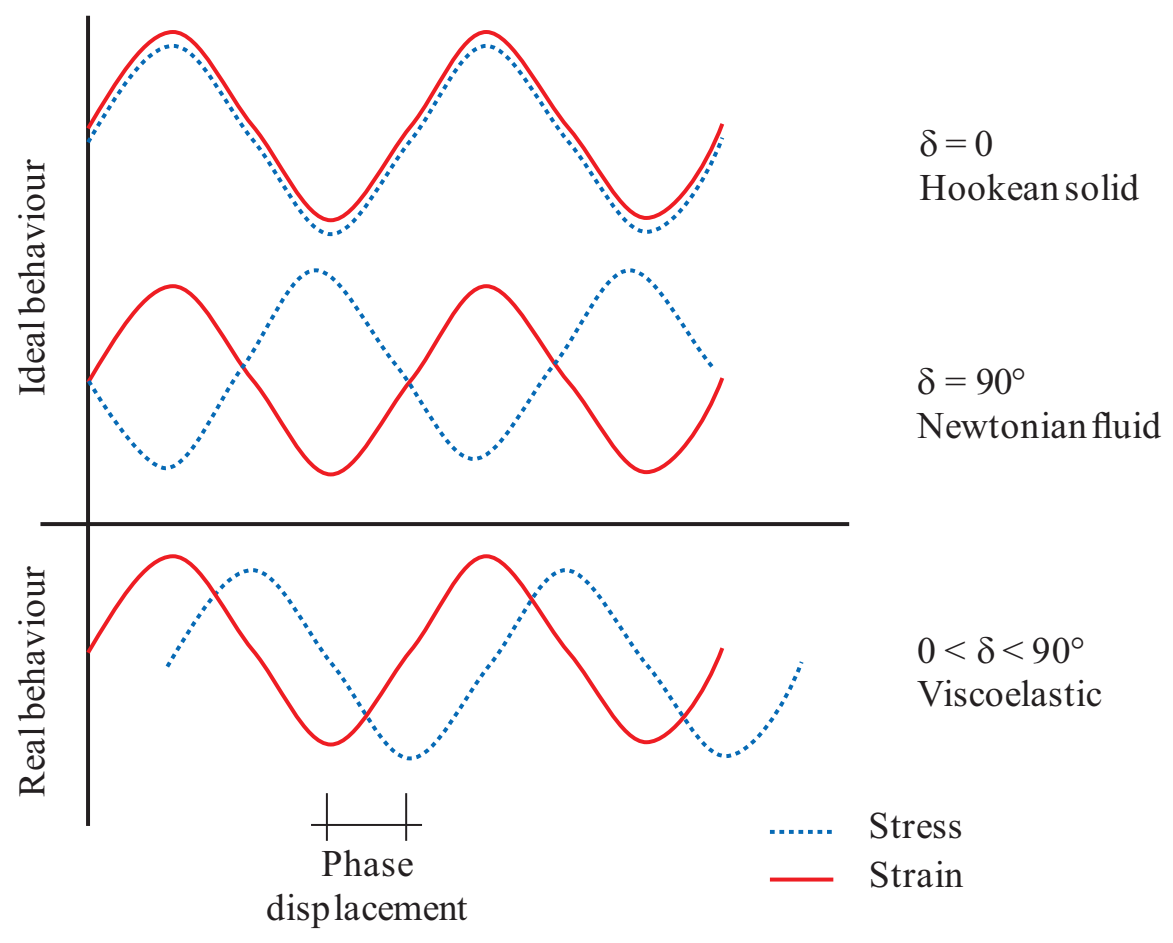

\section{Figure 2}

Illustration of oscillatory test, applying a sinusoidal strain, obtaining the stress as a response, when the material is ideal (Hookean solid or Newtonian fluid) and real (viscoelastic) 


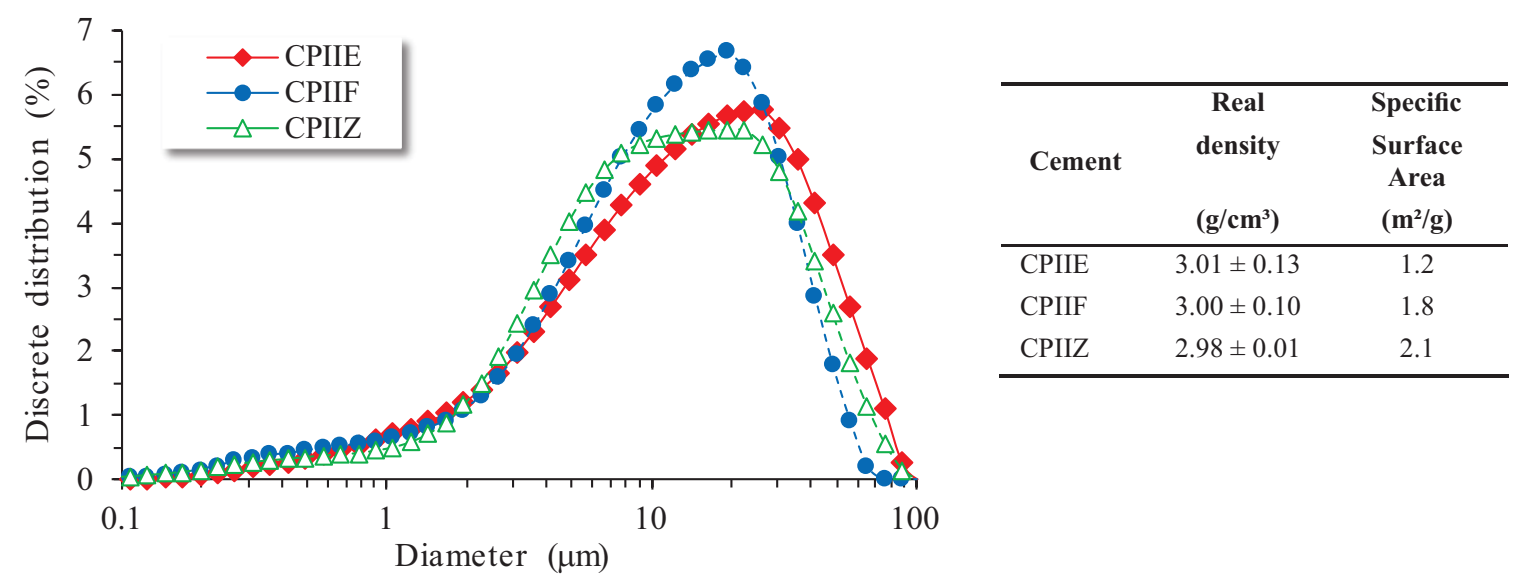

\section{Figure 3}

Particle size distribution, real density and specific surface area of Portland cements

with blast furnace slag, melilite $\left((\mathrm{Ca}, \mathrm{Na})_{2}\left[\mathrm{SiO}_{7}\right]\right)$ and merwinite $\left(\mathrm{Ca}_{3} \mathrm{Mg}\left(\mathrm{SiO}_{4}\right)_{2}\right)$ phases were observed as well as the characteristic halo of the glassy phase.

\subsection{Mixing procedure}

Two practical possibilities for processing cement pastes are commonly used for technical/scientific purposes: maintenance of consistency or maintenance of water-to-cement ratio. In the construction site, the cementitious materials are mixed based on the consistency, altering the quantity of water, keeping the same characteristics during the transportation or application. This procedure is a common laboratory practice choosing a constant consistency for evaluating the properties of cementitious materials.

The second possibility applied, that is, the water-to-cement ratio maintained constant; the characteristics of suspensions during the flow are affect, depending on the physico-chemical characteristics of the binder. This practice was adopted in this work.

In this way, the suspensions were mixed for 1 minute at $1500 \mathrm{rpm}$ in a RW 20 mixer (IKA, Labortechnik) and, after homogenization, the particles were dispersed in a high energy mixer, IKA T25 Basic, at $9500 \mathrm{rpm}$ for 1.5 minutes, using a water-to-cement ratio of 0.4 .

\subsection{Methods}

Isothermal calorimetry, oscillatory rheometry and Vicat tests were carried out at room temperature $\left(23^{\circ} \mathrm{C} \pm 2\right)$, applied to make a comparable analysis of results.

Vicat test: carried out using automatic equipment, ELE, with the needle penetration control for each 15 minutes.

- Isothermal conduction calorimetry: heat flow during the hydration reactions was monitored in a TAMAir calorimeter from TA Instruments with precision of $\pm 20 \mathrm{~mW}$, maintaining the temperature at $23^{\circ} \mathrm{C}$ for 48 hours.

- Oscillatory rheometry: tests were performed in an AR550 rheometer by TA Instruments with parallel plate geometry of 40 $\mathrm{mm}$ and a gap of $1000 \mathrm{~mm}$, according presented in Figure 5. Pastes' consolidation was monitored for 4 hours at a constant frequency of $1 \mathrm{~Hz}$ and a strain of $10^{-4}$. During the tests, a solvent trap was used to maintain the humidity [25].

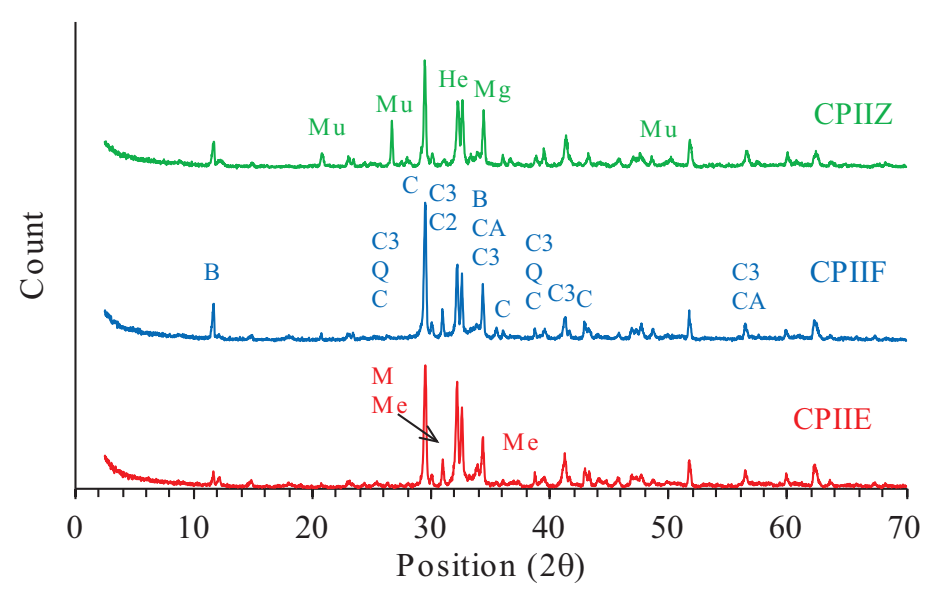

\begin{tabular}{cc}
\hline Reference & Mineralogical phase \\
\hline $\mathrm{CA}$ & Calcium aluminate \\
$\mathrm{B}$ & Brownmilerite \\
$\mathrm{C}$ & Calcite \\
$\mathrm{C} 2$ & Belite \\
$\mathrm{C} 3$ & Alite \\
$\mathrm{He}$ & Hematite \\
$\mathrm{M}$ & Merwinite \\
$\mathrm{Me}$ & Melilite \\
$\mathrm{Mg}$ & Magnetite \\
$\mathrm{Mu}$ & Mullite \\
$\mathrm{Q}$ & Quartz \\
\hline
\end{tabular}

Figure 4

Mineralogical compositions of cements 

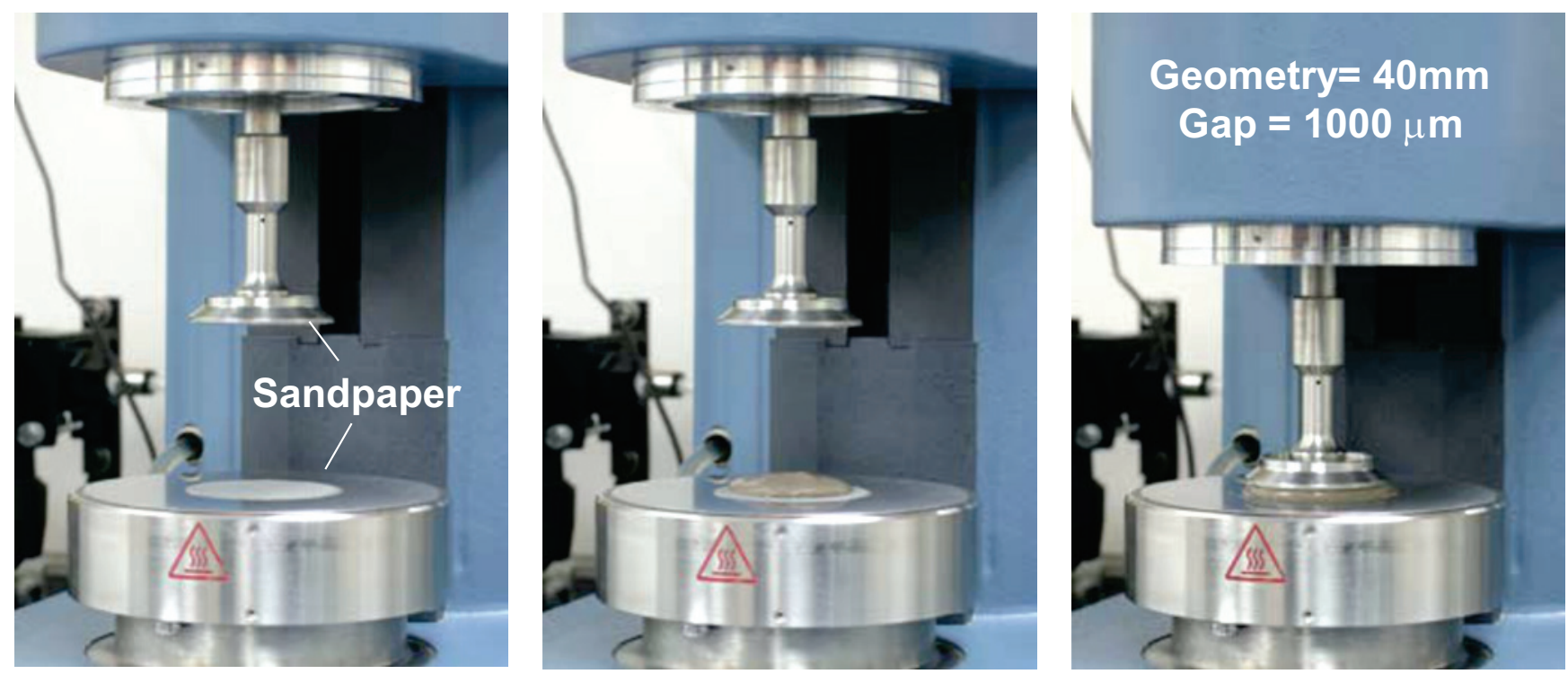

\section{Figure 5}

Equipment used for oscillatory rheometry. Sandpaper was glued on the Peltier plate and under the geometry to prevent paste slipping during the test

\section{Results and discussion}

\subsection{Setting time - Vicat test}

Setting is a process in which a fresh cement paste is converted into a set material which has lost its unlimited deformability under the effect of a sufficiently great external force. This is a spontaneous process of all inorganic binders. Figure 6 presents the setting time for each cement, which are in agreement with Brazilian Standard ( $\geq 1$ hour). In the graph, $40 \mathrm{~mm}$ represents the complete needle penetration, and the setting time occurs when the resistance of paste results in a penetration of $0.5 \mathrm{~mm}$ (or $39.5 \mathrm{~mm}$ in the graph).
As this is a result based on an empirical criterion adopted, an important question is: can a physico-chemical phenomenon, as the consolidation, be quantified only through its physical contribution, using a mechanical and destructive method like Vicat needle, whose response is the opposing resistance from the in developing structure to the needle penetration?

The answer is not so simple, but it can be affirmed that Vicat test does not provide reliable information about the contribution of the chemical phenomena to the transition from fluid-to-solid of cementitious suspensions.

From the beginning of hydration ( $\mathrm{t}=0)$ until, at least 180-190 minutes, depending on the type of cement, it was not observed any alteration on the needle penetration. So, up to 3 hours of testing no

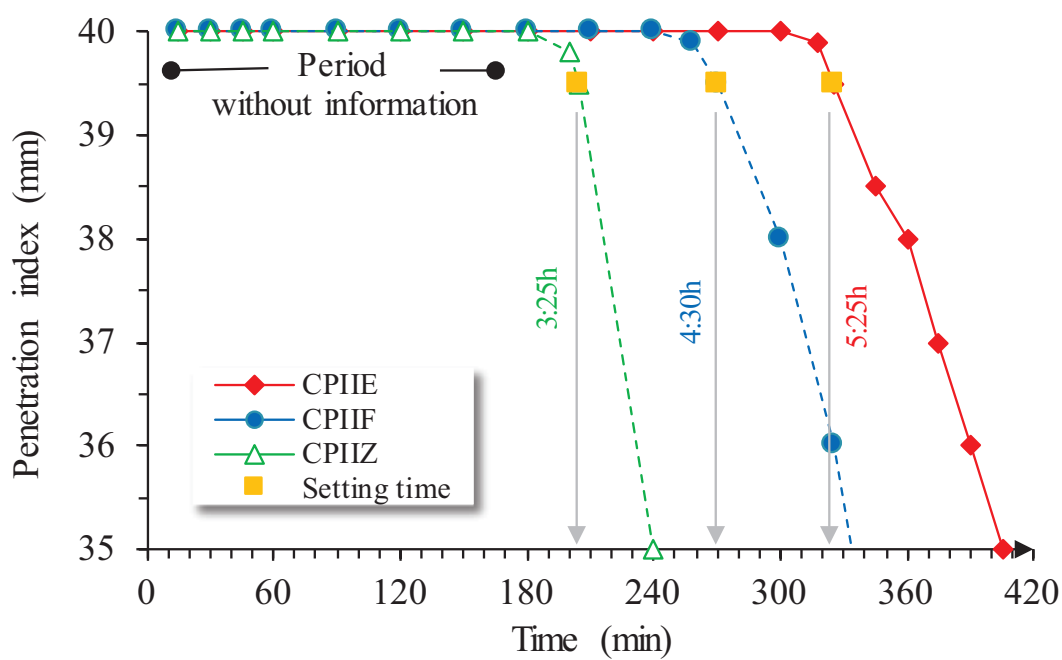

Figure 6

Monitoring of Vicat needle penetration for each suspension in function of time 
information was obtained for CPIIZ. For CPIIE this result is even worst and up to 320 minutes no information was quantified. It is fair to say that even without any quantification according to the Vicat test, changes on the microstructure formation are occurring since the first contact of water and dry-powder. Consequently, a range of industrial process, like rendering mortars, self-leveling concrete, pre-cast structures, and other processes, are affected.

At this way, it can be said that the monitoring hardening is not continuously determined, but this not means that nothing is happening in this period. The hydration reaction of $\mathrm{C}_{3} \mathrm{~S}$ is occurring with the calcium silicate hydrate growing out around of anhydrous grains, what corresponds to the workability period of cement pastes [19]. So, no information about the chemical reactions during the setting process is obtained.

As is a common sense, the particle agglomeration or dissolution beginning of clinker phases and calcium sulfate occurs since the first contact of cement and water [2].

After this period, the progress in setting time is related with the evolution of chemical reactions, in the acceleration period, in which the hydrated products formed, C-S-H and portlandite, link the particles together, as show in Figure 7. This period can be credited to the time needed for the maximum particle agglomeration: the interaction between highly charged C-S-H particles in the presence of divalent calcium counter-ions is strongly attractive because of ion-ion correlations and a negligible entropic repulsion [2].

These initial phenomena are affected by the use of clinker supplementary cementitious materials substitution, as limestone filler, pozzolans and blast furnace slag, as is observed with the quantification of setting time: for CPIIZ, the setting was 3:25 hours while for CPIIF was 4:30 hours, and for CPIIE was 5:25 hours.

\subsection{Heat release during the hydration reaction - Isothermal calorimetry}

The contribution of the chemical reactions can be followed by the heat released during the early hydration period. Figure 7 shows their heat flow released for the first 30 hours (above) and the cumulative heat (below). The symbol $\square$ represents the setting time, obtained by Vicat test. Additionally, on the right is presented the cumulative heat in each initial setting time.

The hydration of Portland cement consists of a series of simultaneous and successively reactions between individual clinker phases, calcium sulfates and water, all of which proceed at different rates. The progress of this process depends on the rate of dissolution of the involved phases (which controls the beginning of hydration reaction), the rate of nucleation and crystal growth of the hydrates

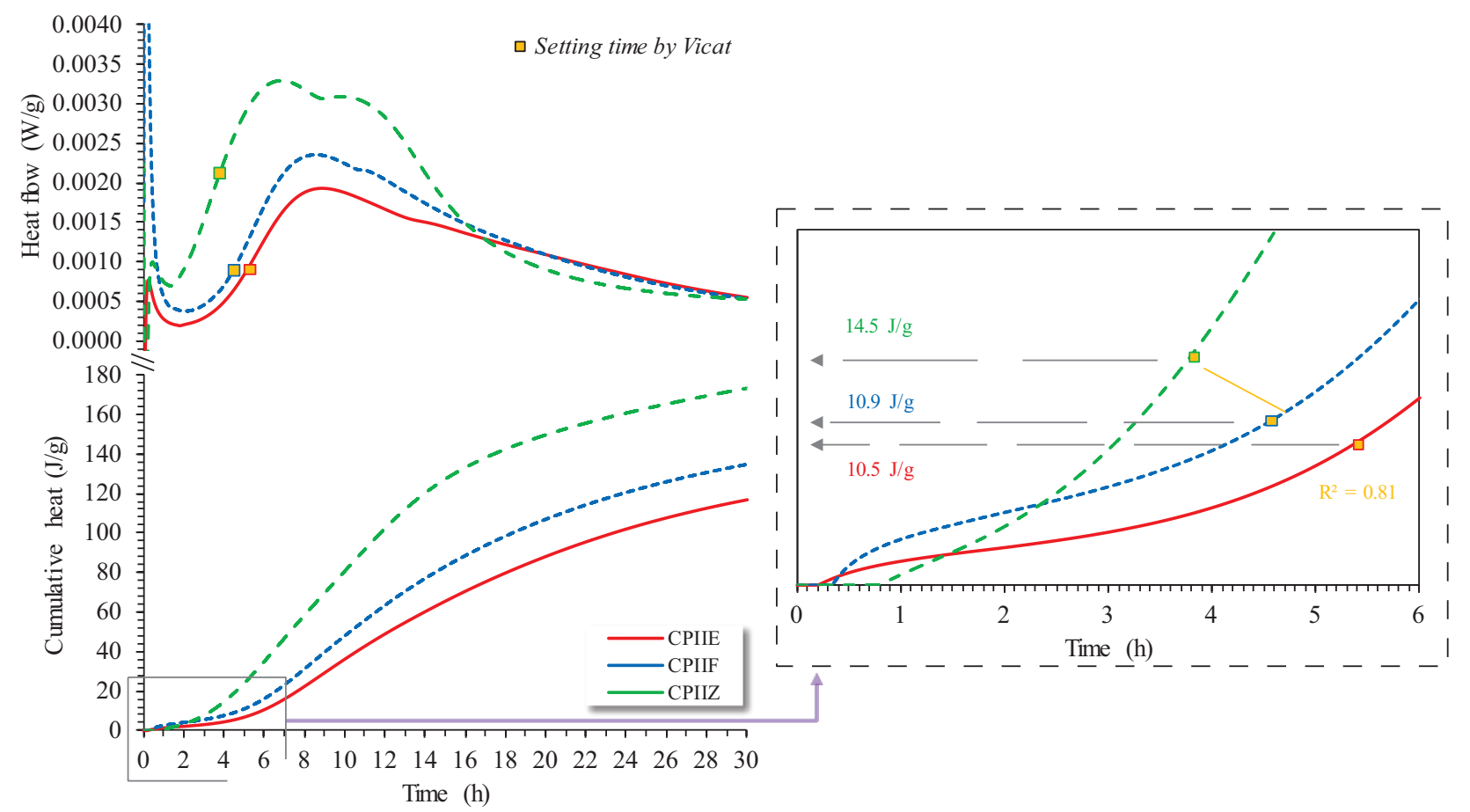

\begin{tabular}{|c|c|c|c|c|c|}
\hline Cement & $\begin{array}{c}\text { Reaction rate } \\
\text { (mW/g.h) }\end{array}$ & $\begin{array}{c}\text { Cumulative heat } \\
\text { at initial setting } \\
\text { (J/g) }\end{array}$ & $\begin{array}{c}\text { Induction period } \\
\text { (h:min) }\end{array}$ & $\begin{array}{c}\text { Setting time } \\
\text { by Vicat } \\
\text { (h:min) }\end{array}$ & $\begin{array}{c}\text { End of acceleration } \\
\text { period } \\
\text { (h:min) }\end{array}$ \\
\hline CPIIE & 0.50 & 10.5 & $2: 40$ & $5: 25$ & $8: 05$ \\
\hline CPIIF & 0.60 & 10.9 & $2: 30$ & $4: 30$ & $7: 40$ \\
\hline CPIIZ & 0.84 & 14.5 & $1: 00$ & $3: 25$ & $6: 10$ \\
\hline
\end{tabular}

\section{Figure 7}

Flow heat during the hydration reaction (above) and cumulative heat (below). The table shows the reaction rate, cumulative heat in the setting time, induction period and the end of the acceleration period 
to be formed, and the rate of water diffusion and dissolved ions through the hydrated material already formed.

Supplementary cementitious materials have two effects on hydration kinetics [26]: the dilution of the clinker phase and the nucleation accelerating the precipitation of the $\mathrm{C}-\mathrm{S}-\mathrm{H}$ and $\mathrm{CH}$.

So, as shown in Figure 6 it can be differentiated the nucleation effect for limestone filler [27-30] and pozzolan additions, and the dilution effect for blast furnace slag addition with the highest end of acceleration period.

To quantify the progress of hydration reactions was used the global degree of hydration ( $\alpha$ ), defined as the ratio of heat evolved at a time $t(Q t)$ to the total (and theoretical) heat of hydration of cement $\left(Q^{\infty}\right)$. The results show that the setting time occurs in the paste of CPIIE with just $2 \%$ of $\alpha$, but for the pastes with limestone filler and pozzolan, was necessary $9 \%$ and $10 \%$, respectively.

The heat flow is directly related with the type of cement and was more pronounced in the suspension with the cement with pozzolan. For this cement, the induction period was lower, the reaction rate higher, and the end of acceleration period was, consequently, reduced, generating more $\mathrm{C}-\mathrm{S}-\mathrm{H}+\mathrm{CH}$ and faster. After 30 hours of hydration, the cumulative heat was the highest than for the other two cements.

Independently of the hydration kinetics, the setting times, quantified by Vicat test, were observed in the acceleration period, converging with ASTM designation C1679-13, Standard Practice for Measuring Hydration Kinetics of Hydraulic Cementitious Mixtures Using Isothermal Calorimetry.

During the induction period and at the beginning of the acceleration stage, the flocculation of the paste is reversible and any external disturbing may destroy the structure, which is rebuilt again upon renewed standing. The apparent viscosity of the paste also increases due to a progressive hydration of the cement that results in a gradual increase of a roughening of

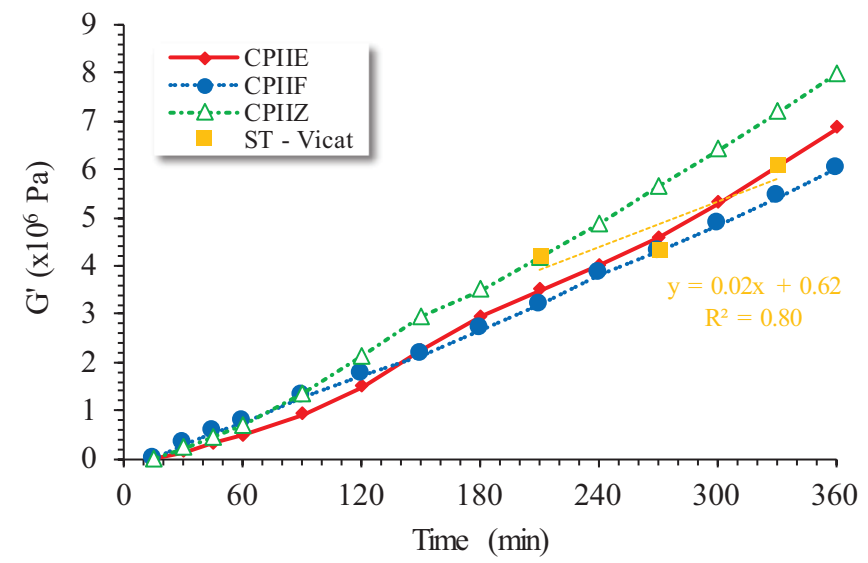

\begin{tabular}{|c|c|c|c|}
\hline Cement & $\begin{array}{c}\text { Consolidation } \\
\text { rate } \\
\left(\mathbf{1 0}^{\circ} \mathbf{P a} / \mathbf{m i n}\right)\end{array}$ & $\begin{array}{c}\mathbf{G}^{\prime} \text { on the } \\
\text { setting time } \\
(\mathbf{1 0} \mathbf{P a})\end{array}$ & $\begin{array}{c}\text { Setting time } \\
\text { by Vicat } \\
\text { (h:min) }\end{array}$ \\
\hline CPIIE & 0.020 & 6.1 & $5: 25$ \\
\hline CPIIF & 0.017 & 4.3 & $4: 30$ \\
\hline CPIIZ & 0.023 & 4.2 & $3: 25$ \\
\hline
\end{tabular}

Figure 8

$G^{\prime}$ data in function of time the cement particles surface, caused by precipitation of the hydrates formed.

However, in the acceleration period of hydration, the amount of hydrated material increases quickly and along with the volume of the liquid phase simultaneously decreases. The solution becomes oversaturate in calcium ions, and the nanoparticles of calcium-silicate-hydrate grows up around the cement grains, forming a network that fills the spaces between them [31].

Therefore, chemical bonds develop at the contact points between the individual cement particles covered with the hydrated material. The latter contacts are stronger than the early ones' due to van der Waals and electrostatic forces, which are responsible for flocculation, and are not restored if broken down.

The dissolution of clinker phases is the limiting parameter to determine the reaction rate, affected by the ion concentration in the solution [20]. In fact, it was noticed that Portland cement with blast furnace slag presented slower reaction rate in comparison with the Portland cements blended with limestone filler or pozzolan, occurring the slag reaction later than clinker phases.

\subsection{Kinetic of cement consolidation - oscillatory rheometry}

Oscillatory test was used for monitoring the consolidation of cementitious suspensions. It is essential that the tests be carried out in the linear viscoelastic region (LVR), in which the elasticity modulus is not dependent of the applied strain, below the critical point. Such region is limited by the critical strain $\left(\mathrm{g}_{0}\right)$ applied during the test [4].

Figure 8 correlates the results of the evolution of G' versus time. The angular coefficient represented the rate of consolidation: as higher the inclination, higher the cement consolidation rate is.

The increase on $\mathrm{G}^{\prime}$, or on $\mathrm{s}_{0}$ in function of time [4], occurs due to particle attractive forces, van der Waals interactions and electrostatic forces, promoted by the dissolution and precipitation of cement hydrates; the result is a quick growth in the cement specific surface area, due to the C-S-H, portlandite and Aft formation.

The consolidation patterns were similar, but cement dependent. For CPIIF the storage modulus in the beginning of the test was the highest due to the quick re-agglomeration after shearing stopped, but the rate of consolidation is the lowest of the studied binders.

For CPIIE, it is clear that, in the setting time, the microstructure formed had greater stiffness than in the other cements, proving that the needle penetration does not stop just due to a rheological variable; other properties must be taken into account when assessing the Vicat test.

On the suspensions with CPIIZ, after two hours, the G' values were higher than the other two evaluated cements, but the value of the setting time was the lowest.

These observations prove that the setting time, although with a good correlation with G' value, cannot be explained just by the microstructural stiffening. Each binder has its peculiarities during the hardening and microstructural formation.

Using oscillatory rheometry was possible monitoring continuously the evolution of ' $\mathrm{G}^{\prime}$, since the first minutes of hydration. In other words, the changes in the yield stress were continuously monitored since the beginning of consolidation [4]. 


\subsection{Combined analysis}

The three methods employed provide information about different aspects of the cement pastes consolidation, but the possibility of being correlated can be an alternative for a better understanding the hardening.

The chemical process leads to the formation of hydrates compounds from the anhydrous cement, changing the physical properties over time. Consequently, the transition from fluid to solid state occurs increasing the strength of the material, and the setting time is a definite time to compare this transition for different binders.

Figure 9 shows the relationship between the results obtained by oscillatory rheometry and by isothermal calorimetry, indicating the setting time for each paste. While the first represent the physical contribution to the hardening process, the second one represents the chemical contribution. In both cases, the representative results were obtained continuously, from the beginning of test, different of Vicat results.

The raise of G' value over time occurs due to attractive forces between particles, but the main interaction is not yet well known. Nonat et al. [2] proved that the ionic constitution of solution surrounding each particle plays an important role. The dissolution of $\mathrm{C}_{3} \mathrm{~S}$ particles results in calcium, silicate and $\mathrm{OH}^{-}$ions, which are fixed by the solubility equilibrium of $\mathrm{C}-\mathrm{S}-\mathrm{H}$. Because of this, an increase of $\mathrm{Ca}^{2+}$ concentration results in a decrease of silicate concentration. Therefore, changes in chemical reaction are very important.

It is clear that for all suspensions there was a quick improvement on G', even with lower heat release. Moreover, in the suspension of cement with limestone filler, it was necessary higher heat release to achieve the same G' value of CPIIE or CPIIZ.

The consolidation occurs as soon as calcium concentration reaches about $10 \mathrm{mmol} / \mathrm{L}$, whatever the percentage of precipitated hydrates. If the calcium concentration cannot reach this threshold value at complete hydration of $\mathrm{C}_{3} \mathrm{~S}$, consolidation never occurs. This clearly shows that hydration is not sufficient for setting. Indeed, this threshold value corresponds to the concentration at which the solubility of $\mathrm{C}-\mathrm{S}-\mathrm{H}$ in solution becomes very slow [2].

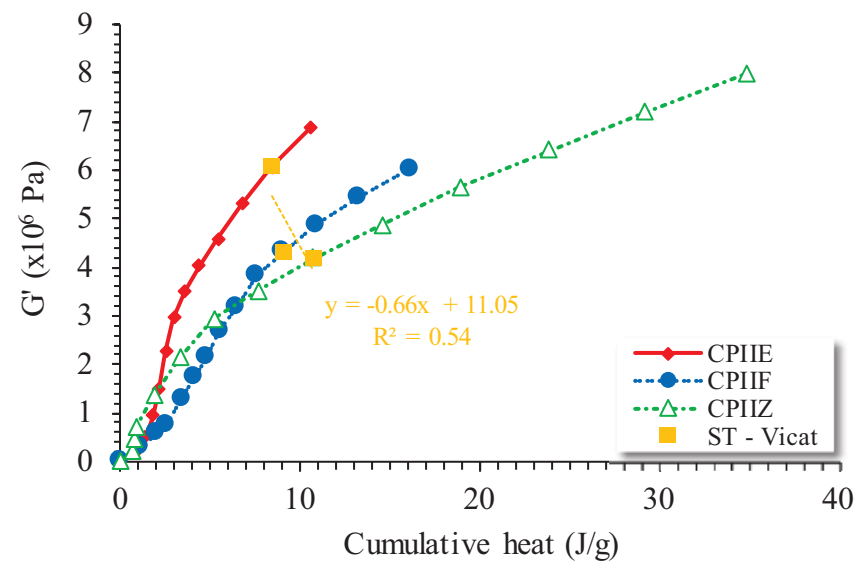

Figure 9

Relationship between the rate of chemical reaction and the consolidation rate

This information may be true, but is not only the $\mathrm{Ca}^{2+}$-release that governs the setting.

The correlations presented in Figure 10, shows that the penetration index during the Vicat test does not have relationship with heat release or with the G' value, neither.

This is a confirmation that the hardening process presents two complementary phenomena: one at the origin of the contacts between particles, and another through hydrates contacting points formed between anhydrous particles under reaction.

During the Vicat test, the needle penetration occurs under high shear rate, disrupting the agglomeration over time, and the rheological test, as carried out, do not represent the main event during the penetration. On the other hand, as the link between the agglomerates becomes stronger, due to the chemical reaction, the penetration index decreases. Therefore, it can be said that the chemical reaction is necessary, but not sufficient.

Figure 11 shows the ratio G'/cumulative heat over time, a way to indicate the physical-chemical parameter of hardening. Additionally, is presented the setting time. This kind of evaluation is an alternative to quantify the impact of chemical reaction on the gain of
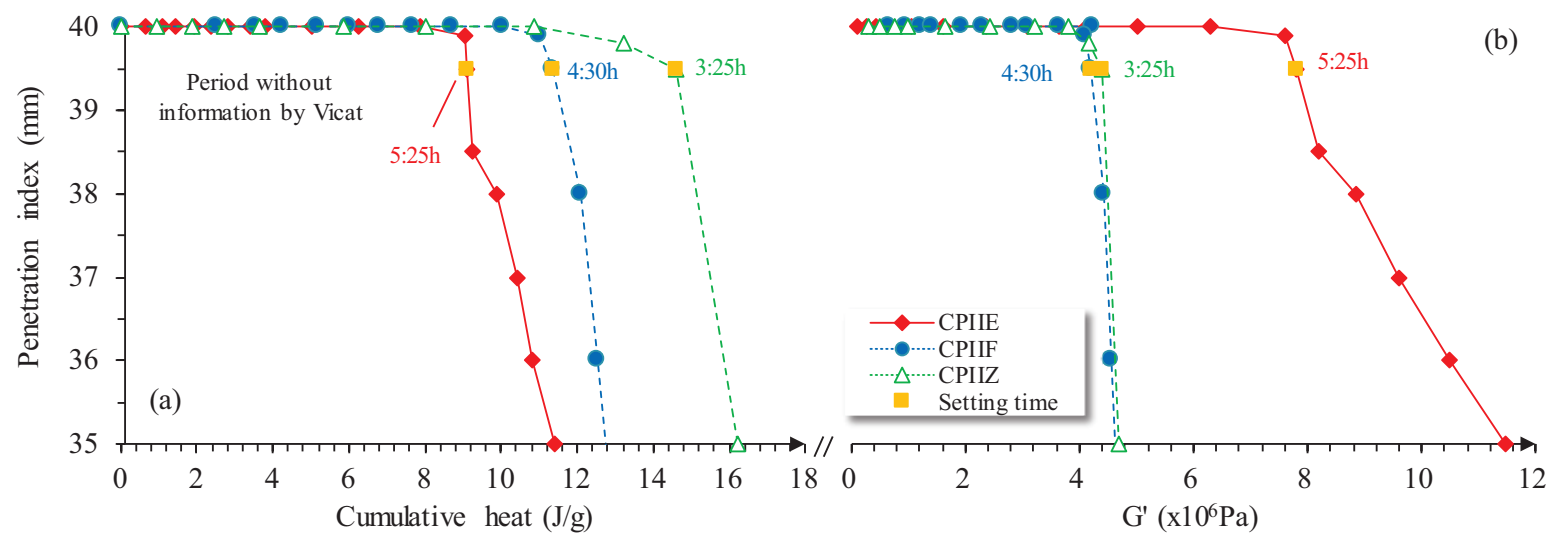

\section{Figure 10}

Relationship between penetration index monitored by Vicat test and cumulative heat accompanied by isothermal calorimetry. The setting times of each paste are presented 


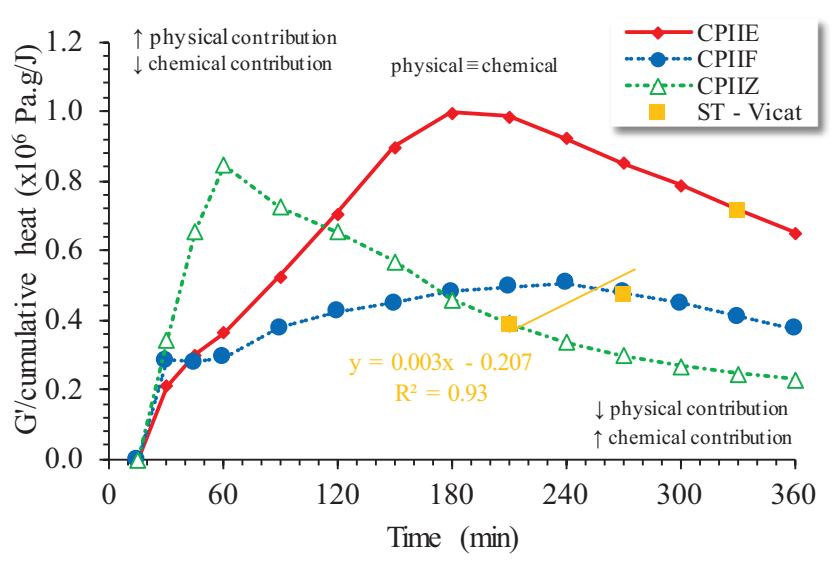

Figure 11

Relationship between setting time, measured by Vicat test, $G^{\prime}$, and the ratio $G^{\prime}$ / cumulative heat, represent both chemical and physical contribution to hardening

consistence of suspension, which represents how much the chemical reaction changes the rheological parameters.

In the beginning of hardening, the contribution of physical parameter is more intense than the chemical parameter. This is because the natural tendency to particle agglomeration, due to attractive forces, van der Waals interactions and electrostatic forces, occurs in any fine particle in contact with water. At the same time, the precipitation of hydrated compounds is still slow.

CPIIE and CPIIF have a plateau from 60 to 240 minutes, depending on the binder, which represents that the physical and chemical parameters are in equilibrium. This means that changes in hydration reaction are simultaneously changing the cement surface and increasing electrostatic forces.

The setting times were observed when the ratio G'/cumulative heat was decreasing, which means that the chemical contribution is more intense than the physical one. Before this stage the flocculation of the paste is reversible and any external disturbance may destroy the structure, but the intensification of chemical reaction increases the linking between agglomerates, difficulty the needle penetration. As stronger the microstructure formed, lower the ratio G'/cumulative, resulting in lower setting time.

From these observations, it can be confirmed that the setting time is influenced by both contributions, because the physical phenomena changes continuously in function of a cement chemical reaction.

So, to understand the setting depends on the knowledge of the processes involved in that transformation and of the parameters that determining the mechanism. Both agglomeration and rigidification processes depend on calcium and silicate concentrations in solution, which are determined by the chemistry of the $\mathrm{CaO}-\mathrm{SiO}_{2}-$ $\mathrm{H}_{2} \mathrm{O}$ system.

\section{Conclusions}

The results of Vicat test showed the differences between the Portland cements setting times caused by different SCM's added, and no relevant data, before and/or after the setting time, were quanti- fied. Applying this method, the information about the consolidation is empirical and arbitrary, and no information about de chemical reactions or about the development of microstructure were obtained. Monitoring the consolidation rate through a rheological test provides continuous information about the yield stress evolution, represented by G', since the first moment after mixing. This is the contribution of the physical phenomena to the consolidation.

As cement develops its structure continuously in contact with water, monitoring the heat release makes possible to compare the chemical contribution in the consolidation process, in function of SCM's. To follow the evolution of chemical reactions is a good tool, but not sufficient, because if the structure formed is broken as in Vicat test, it will be needed more time of hydration to restore the particles linking, affecting the real time of consolidation. In this way, it is very important to say that the beginning and the end of setting time, respectively, is an incorrect form to evaluate the consolidation.

The calculated ratio G'/cumulative heat seems to be the best way to associate the physical-chemical phenomena with the setting time and with the transition from fluid-to-solid behavior.

In short, the association of these complementary techniques, which evaluates these phenomena separately, was very useful to the understanding of SCM's effect in the transition behavior from fluid to solid, observed for the analyzed cements:

- CPIIZ with pozzolan and limestone filler: quick consolidation rate, fast reaction rate and lower initial setting time due to the synergic effect of both additions;

- CPIIE with blast furnace slag and limestone filler: the highest initial setting time due to its slow development of early coagulated structure and lower reaction rate;

- CPIIF presented intermediate behavior, independent of method used to the evaluations.

The results obtained for these three binders, with different SCM's, showed that their performance are quite different, from the point of view of early hydration, and consequently it may be questioned if they can be considered interchangeable in concrete mixes or mortars for a same destination.

\section{Acknowledments}

The authors are thankful to CNPq - National Council for Scientific and Technological Development (research grant 155357/2016-6) and to Laboratory of Microstructure and Ecoefficiency of Materials, by the financial support to carry out this work.

\section{References}

[1] LOTHENBACH, B., SCRIVENER, K. L., HOOTON, R. D. Supplementary cementitious materials. Cement and Concrete Research 41 (2011) 1244-1256.

[2] NONAT, A., MUTIN, J. C., LECOQ, X., JIANG, S. P. Physico-chemical parameters determining hydration and particle interactions during the setting of silicate cements. Solid State lonics 101-103 (1997) 923-930.

[3] LOOTENS, D., JOUSSET, P., MARTINIE, L., ROUSSEL, N., FLATT, R. J. Yield stress during setting of cement pastes from penetration tests. Cement Concrete Research, 39 (2009) $401-408$. 
[4] ROMANO, R. C. O., LIBERATO, C. C., MONTINI, M., GALLO, J. B., CINCOTTO, M. A., PILEGGI, R. G. Evaluation of transition from fluid to elastic solid of cementitious pastes with bauxite residue using oscillation rheometry and isothermal calorimetry. Applied Rheology, 23:2 (2013) 23830

[5] CHEN, Y., ODLER, I. On the origin of Portland cement setting. Cement and Concrete Research 22 (1992) $1130-1140$.

[6] YANG, M., NEUBAUER, C. M., JENNINGS, H. M. Interparticle potential and sedimentation behavior of cement suspensions, Advn. Cem. Bas. Materials, 5 (1997) 1-7.

[7] YLMÉN, R., JÄGLID, U., STEENARI, B-M, PANAS, I. Early hydration and setting of Portland cement monitored by IR, SEM and Vicat techniques. Cement Concrete Research 39 (2009) 433-439.

[8] BELLOTTO, M. Cement paste prior to setting: a rheological approach. Cem. Conc. Res. 52 (2013) 161-168.

[9] STRUBLE, L. J., LEI, W. G. Rheological changes associated with setting of cement paste. Advanced Cement Based Materials, 2 (1995) 224 - 230.

[10] ZHANG, J., WEISSINGER, E. A., PEETHAMPARAN, S., SCHERER, G. W. Early hydration and setting of oil well cement. Cement Concrete Research 40 (2010) 1023 - 1033.

[11] SANT, G., FERRARIS, C. F., WEISS, J. Rheological properties of cement pastes: a discussion of structure formation and mechanical property development, Cement and Concrete Research 38 (11) (2008) 1286 $-1296$.

[12] SLEIMAN, H., PERROT, A., AMZIANE, S. A new look at the measurement of cementitious paste setting by Vicat test. Cement Concrete Research 40 (2010) 681 - 686 .

[13] XU, Q., HU, J., RUIZ, J. M., WANG, K., GE, Z. Isothermal calorimetry tests and modeling of cement hydration parameters. Thermochimica Acta 499 (2010) 91-99.

[14] ROMANO, R. C. O., TAKAHASHI, M. M., LIBERATO, C. C., PILEGGI, R. G. Fresh and hardened characterization of air-entrained cement pastes. In. 13th International Congress on the Chemistry of Cement, 2011, Madrid - Espanha.

[15] ODLER, I., HAGYMASSY, J., YUDENFREUND, M., HANNA, K., BRUNAUER, S. Pore structure analysis by water vapor adsorption IV. Analysis of hydrated Portland cement pastes of low porosity. J. Colloid Interface Sci. 38 (1972) 265-276.

[16] ODLER, I., Hydration, setting and hardening of Portland cement. IN: Lea's Chemistry of Cement and Concrete, Cap. 6, 1998, Arnold Ed., N.Y., 1053 p.

[17] MINARD, H., GARRAULT, S., REGNAUD, L., NONAT, A. Mechanisms and parameters controlling the tricalcium aluminate reactivity in the presence of gypsum. Cement Concrete Research, Vol. 37. p.1418-1426, Issue 10, October 2007.

[18] BULLARD, J.W, JENNINGS, H. M., LIVINGSTON, R.A., NONAT, A., SCHERER, G.W., SCHWEITZER,
J.S., SCRIVENER, K. L., THOMAS, J. J. Mechanisms of cement hydration, Cement Concrete Research, 41 (2011) 1208-1223.

[19] GARRAUT, S., NONAT, A., SALLIER, Y., NICOLEAU, L. On the Origin of the Dormant Period of Cement Hydration. In. 13th International Congress on the Chemistry of Cement. Madrid. 2011

[20] JUILLAND, P., GALLUCCI, E., SCRIVENER, K., L., FLATT, R. J. Mechanisms of hydration of cementitious materials at early age. In. 13th International Congress on the Chemistry of Cement. Madrid. 2011.

[21] ZHENG, J. J., ZHANG, J., SCHERER, G. W. Prediction of the degree of hydration at initial setting time of cement paste with particle agglomeration. Cement and Concrete Research 42 (2012) 1280-1285

[22] FLATT, R. J. Dispersion forces in cement suspensions. Cement and Concrete Research 34 (2004) 399 - 408.

[23] ROUSSEL, N., LEMAITRE, A., FLATT, R. J. COUSSOT, P. Steady state flow of cement suspension: a micromechanical state of the art. Cement Concrete Research 40 (2010), $77-84$.

[24] ROMANO, R. C. O., PILEGGI, R. G. Temperature's role in the rheological behavior of cementitious pastes prepared with air-entraining admixtures. Applied Rheology, 22 (2012) 24333.

[25] FUJII, A. L., TORRES, D. R., ROMANO, R. C. O., CINCOTTO, M. A., PILEGGI, R. G. Impact of superplasticizer on the hardening of slag Portland cement blended with red mud. Construction and Building Materials 101 (2015) 432-439.

[26] LAWRENCE, P., CYR, M., RINGOT, E. Mineral admixtures in mortars. Effect of inert materials on short-term hydration. Cement and Concrete Research 33 (2003) 1939-1947.

[27] CHOWANIEC, O. Limestone addition in cement. EPFL - Thesis 5335, 2012.

[28] DE WEERDT, K., BEN HAHA, M., LE SAOUT, G., KJELLSEN K.O., JUSTNES, H, LOTHENBACH, B. Hydration mechanisms of ternary Portland cements containing limestone powder and fly ash, Cement and Concrete Research 41 (2011) 279-291.

[29] KAKALI, G., TSIVILIS, S., AGGELI, E., AND BATI, M. Hydration products of C3A, C3S and Portland cement in the presence of $\mathrm{CaCO} 3$. Cement and Concrete $\mathrm{Re}$ search 30 (2000), 1073-1077.

[30] KUMAR, A., OEY, .T, KIM, S., THOMAS, D., BADRAN, S., LI, J., FERNANDES, F., NEITHALATH, N., SANT, G. Simple methods to estimate the influence of limestone fillers on reaction and property evolution in cementitious materials, Cement and Concrete Composites 42 (2013) 20-29.

[31] JONSSON, B., WENNERSTROM, H., NONAT, A., CABANE, B. Onset of Cohesion in Cement Paste. Langmuir 20. 2004. 6702-6709. 